\title{
Carmine allergy in urticaria patients
}

\author{
Beata Sadowska, Marlena Sztormowska, Marika Gawinowska, Marta Chełmińska
}

Department of Allergology, Medical University of Gdansk, Gdansk, Poland

Adv Dermatol Allergol 2022; XXXIX (1): 94-100

DOI: https://doi.org/10.5114/ada.2020.100821

\begin{abstract}
Introduction: Carmine, a commonly used natural red dye, can cause immediate and delayed allergic reactions, which are frequently overlooked.

Aim: To assess the incidence of carmine allergy and its clinical significance based on the placebo-controlled oral challenge in urticaria patients and suspected hypersensitivity to food additives.

Material and methods: Patients' histories were recorded by means of a standardized questionnaire. The subjects underwent skin prick tests and patch tests for carmine, while the level of specific lgE was measured in 52 patients. The patients with at least one positive carmine test or with suspected hypersensitivity to carmine were suggested to undergo a placebo-controlled oral challenge test.

Results: One hundred and ten patients were enrolled in the study. Carmine skin testing was positive in 22 patients: skin prick tests were positive in $17 \%(n=19)$, while patch tests were doubtful in $6 \%(n=6)$. In $25 / 52$ patients, the level of specific IgE was min. $0.01 \mathrm{kU} / \mathrm{l}$. Oral challenge was performed in 33 subjects. Allergy to carmine was diagnosed in 9 (8\%) patients; all of them suffered from chronic inducible urticaria.

Conclusions: Carmine is a potential allergen in patients with chronic inducible urticaria especially with concomitant systemic symptoms. Skin tests and specific IgE level measurement may be helpful tools to diagnose E120 hypersensitivity.
\end{abstract}

Key words: carmine, cochineal, E-120, food additives, urticaria.

\section{Introduction}

Carmine or less concentrated cochineal extract (E120, Natural Red 4, colour index No. 75470) is a natural red dye obtained from dried bodies of female Dactylopius coccus insects, commonly used in cosmetics, food and pharmaceutical industries [1-5]. According to the European Food Safety Authority (EFSA), cochineal contains approximately 2-4\% of carminic acid only, while commercial carmine used in the industry contains at least $50 \%$ of carminic acid [6]. Protein impurities coming from insects may be responsible for lgEdependent allergic reactions and contact allergy symptoms [5, 7-10]. As neither the Food and Drug Administration (FDA) nor the EFSA has set limits on carmine protein impurities, in practice their content varies and can be as high as 25\% depending on the manufacturer $[9,11,12]$. Ohgiya et al. used sera from patients with anaphylaxis and identified the $38 \mathrm{kD}$ protein CC38K as the main allergen [13].

Symptoms of hypersensitivity may occur after contact with carmine as a result of its ingestion, inhalation or penetration through the skin, resulting in a wide range of reactions including erythema, urticaria, angioedema, exacer- bation of atopic eczema, bronchospasm, extrinsic allergic bronchiolitis, gastrointestinal symptoms and anaphylactic shock [7, 9, 14-17]. Over 80 cases of hypersensitivity have been registered worldwide, predominantly in Japan [18].

It is considered that patients are initially sensitized through their damaged skin when cosmetics with carmine are used (the condition is mainly found in women) or through inhalation during the occupational exposure [7]. The real number of E120 hypersensitivity reactions seems to be underestimated due to the lack of standardized diagnostic methods [18].

\section{Aim}

The aim of the current study was to analyse the frequency of carmine allergy in urticaria patients suspected of being hypersensitive to food additives as revealed via in-depth interviews and questionnaires. To assess the clinical significance of sensitization in selected patients, the authors performed a carmine placebo-controlled oral study. We performed patch tests to determine the fre-

Address for correspondence: Beata Sadowska MD, Department of Allergology, Medical University of Gdansk, 17 Mariana Smoluchowskiego St, 80-214 Gdansk, Poland, phone: +48 604 489 310, e-mail: sadowska.beata@yahoo.pl Received: 9.10.2020, accepted: 24.10.2020. 
quency of carmine contact sensitization and whether it coexists with immediate reactions because the skin can be the primary source of sensitization.

\section{Material and methods}

One hundred and ten urticaria patients, including 76 (69\%) women, were hospitalized at the Allergology Department, Medical University of Gdansk, Poland, in 2017-2019. The study protocol approved by the Bioethics Committee met the ethical standards of the Helsinki Declaration. Written informed consent was obtained from the patients and patient anonymity was preserved using methods approved by the Bioethics Committee. The subjects were also asked to complete a detailed questionnaire about their current course of urticaria. All the patients were asked to stop taking antihistamines and systemic glucocorticoids in the pre-hospitalization period of 7 days and 1 month, respectively. Prior to the study, the intravenous line was placed, blood pressure was measured, and the patients with bronchial asthma underwent spirometry.

Skin prick tests (SPT) were performed for $1 \%$ carmine with positive and negative controls (histamine hydrochloride $10 \mathrm{mg} / \mathrm{mL}$ and Allergopharma saline). The 5\% carmine was provided by Bart Ltd, Stupno, Poland, which was diluted with saline and glycerol at a ratio of $1: 1$ to obtain a $1 \%$ carmine solution. Multiple doses of SPT in attempt to determine the optimal concentration were performed in few patients with positive carmine oral challenge (OC) (Figure 1). The control group comprised 100 patients without urticaria, who were consulted at the outpatient clinic and had negative test results. The two largest perpendicular diameters of the wheal were measured at the $20^{\text {th }}$ and $30^{\text {th }}$ min to calculate the mean value of SPT reaction and were monitored for the next $5 \mathrm{~h}$. The wheal diameter of minimum $3 \mathrm{~mm}$ that was larger than negative control with a wheal reaction of minimum $3 \mathrm{~mm}$ for histamine was considered positive.

Patch tests (PT) for 1\% carmine on petroleum were placed in the chambers of IQ-Ultra Chambers (Chemotechnique Diagnostics, Vellinge, Sweden) on the back of the patients and kept under occlusion for $48 \mathrm{~h}$, and then read after 48, 72, 96 and $168 \mathrm{~h}$.

The serum level of specific IgE was measured by ImmunoCap (cochineal extract, ImmunoCap, code f340, ThermoFisher Scientific). In our study, for research purposes the value of minimum $0.01 \mathrm{kU} / \mathrm{I}$ was initially considered as a positive result, despite the fact that a value $\geq 0.35 \mathrm{kU} / \mathrm{l}$ is usually considered positive.

Patients with positive carmine SPT, f340 or with a history of suspected hypersensitivity to E120 were qualified for a single-blind, placebo-controlled oral challenge. The patients had not taken antihistamines for 7 days, were urticaria symptoms free, with their blood pressure below $140 / 90 \mathrm{~mm} \mathrm{Hg}$ and with the forced expiratory volume in
$1 \mathrm{~s}\left(\mathrm{FEV}_{1}\right)$ above $70 \%$ on the day of the test. According to the protocol, the patients were given a placebo capsule, followed by $1 / 2 / 5 / 10 / 25 / 50 / 100$ and 150 mg carmine capsule. In the case of severe allergic reactions in the past, three initial doses of $0.1 / 0.2 / 0.5 \mathrm{mg}$ were added at the beginning. Doses of $0.1-5 \mathrm{mg}$ were used at intervals of $20 \mathrm{~min}$, and the following doses were given every hour. The Acceptable Daily Intake (ADI), i.e. $5 \mathrm{mg} / \mathrm{kg}$ of body weight according to EFSA [6] was not exceeded. Adverse events were classified as objective symptoms (urticaria, angioedema, rhinitis, conjunctivitis, wheezing, coughing, vomiting, diarrhoea, and collapse) or subjective symptoms. Tests were assessed as positive, when objective allergic symptoms developed during the test, but not after the placebo administration. All the subjects were under observation for a period of at least $3 \mathrm{~h}$ after the last dose administration. The significance of the association of between carmine positive tests and other variables was analysed with the $\chi^{2}$ test/Fisher's exact test.

\section{Results}

\section{Questionnaire}

Over half (51\%) of the patients qualified for the study reported in their questionnaires the occurrence of both

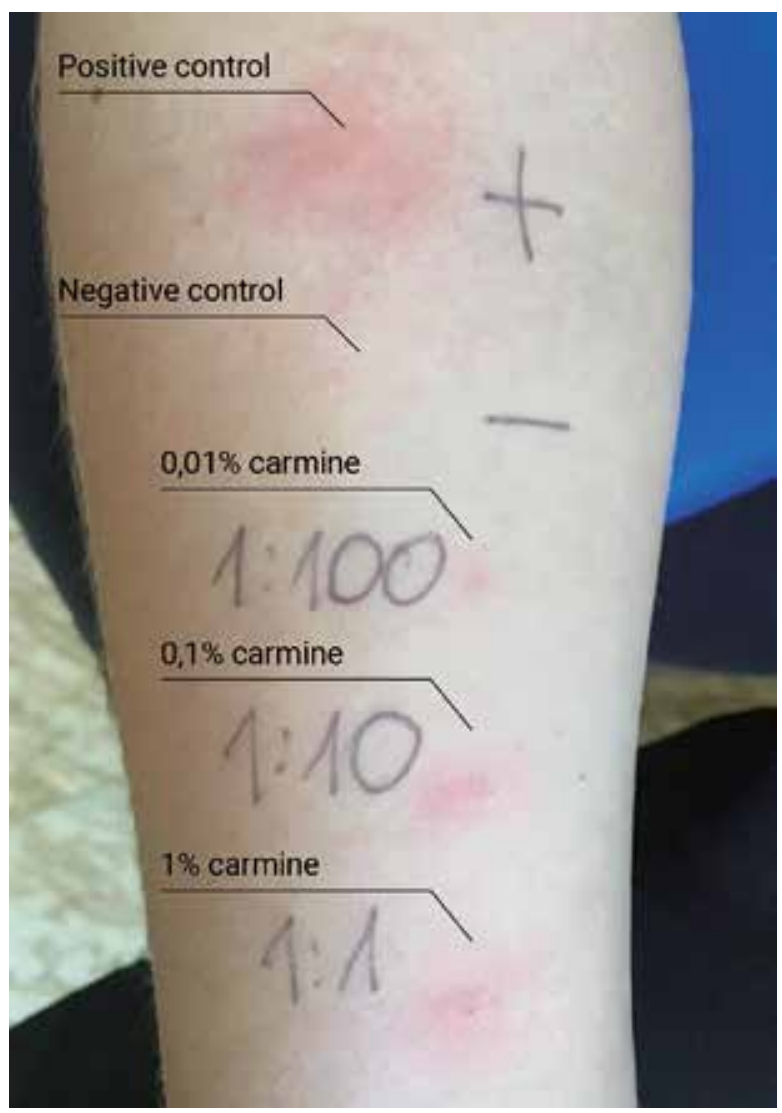

Figure 1. Multiple carmine concentrations of skin prick tests; patient no. 8 
angioedema and urticaria; isolated angioedema was reported in $16 \%$ of the subjects. Fifty-seven percent of patients suffered from chronic spontaneous urticaria (CSU), 65\% had chronic inducible urticaria (CIndU) and $22 \%$ reported both CSU and CIndU.

The patients' average age was 46 years (min. 20, max. 76 years). The duration of the disease was 7 years (min. 3 months, max. 58 years). Every second patient suffered from symptoms less frequently than once a month and $43 \%$ of the patients were treated in the past with parenteral glucocorticoids for an average period of 14 days (1 to 90 days) due to urticaria.

In the group under study, $65 \%$ of the patients had a history of atopy defined as positive SPT or slgE for airborne or food allergens and $23 \%$ of the patients had asthma. Systemic symptoms defined as swelling of the tongue or extracutaneous symptoms associated with urticaria were reported by $56 \%$ of the subjects. Seven out of 10 patients were convinced that it was the food that caused the symptoms. Of the culprit foods, 32 participants listed at least one food potentially containing carmine, such as sausages, kebabs, coloured jelly beans, drops, fruit yoghurts, energy drink, pizza with salami, candied fruit, fruit tea, greengrocer's jams and unidentified spices from the Far East.

\section{Skin prick test - SPT}

The group of patients with a positive carmine SPT, "SPT carmine (+)" group, comprised 19 individuals (17\%). The wheal size increased after 30 min compared to the 20 min evaluation in all the patients. The wheal of $\mathrm{min} .4 \mathrm{~mm}$ in size was observed in 10 participants. In 2 patients (no. 1 and 7), the wheal size increased to the maximum after a few hours (Figures 2 A, B). Compared with patients with a negative SPT, in the SPT carmine (+) group, atopy was usually diagnosed (90\% vs. 59\%, $p<0.01$ ) and the skin manifestation of urticaria was more often accompanied by systemic symptoms ( $84 \%$ vs. $51 \%, p<0.006$ ). A 74-year-old man suffering from angioedema occurring more frequently than once a month, experienced tongue swelling approximately $40 \mathrm{~min}$ after carmine SPT was conducted. The wheal was $6 \mathrm{~mm}$ in size and its $\mathrm{f340}$ value was $0.99 \mathrm{kU} / \mathrm{l}$. The patient's wife confirmed he was developing symptoms after eating red Mentos drops and sausages. This patient was withdrawn from the OC and patch testing and was included in the group of patients with diagnosed carmine hypersensitivity ("carmine hypersensitivity (+)" group).

\section{Patch test - PT}

Six patients had erythema (doubtful result) on the third and fourth day of the carmine patch test. In the patients of the SPT carmine (+) group, the test was doubtful in $16 \%$, the figure being five times higher than that for the SPT carmine (-) group; the difference, however, did not reach any statistical significance $(p<0.063)$.

\section{Specific antibody level - $\mathrm{f340}$}

The $\mathrm{f} 340$ level was measured in 52 subjects suspected of hypersensitivity to carmine, when they answered the questionnaire and also in most patients with a positive SPT and PT (Table 1). The minimum score of 0.01 $\mathrm{kU} / \mathrm{I}$ was detected in 25 subjects (the " $\mathrm{f3} 40$ carmine (+)" group), with an average value of $0.26 \mathrm{kU} / \mathrm{l}$ (the range: 0.01-3.05 kU/l); however the score of $\min .0 .35 \mathrm{kU} / \mathrm{l}$ was

Table 1. Carmine tests performed within the group

\begin{tabular}{|c|c|c|c|c|}
\hline Challenge test & SPT & $\mathrm{f} 340$ & $\begin{array}{l}\text { f340 range }[\mathrm{kU} / \mathrm{l}] \\
\text { (average) }\end{array}$ & $\begin{array}{l}\text { Number of patients indicating food with } \\
\text { potential carmine as the culprit (\%) }\end{array}$ \\
\hline \multirow[t]{3}{*}{$(+) n=9$} & $(+) n=5$ & $(+) n=5$ & $0.02-0.99(0.278)$ & $4(80 \%)$ \\
\hline & $(-) n=4$ & $(+) n=2$ & $0.02-3.05(1.535)$ & $2(100 \%)$ \\
\hline & & $(-) n=2$ & 0 & $1(50 \%)$ \\
\hline \multirow[t]{6}{*}{$(-) n=24$} & $(+) n=9$ & $(+) n=7$ & $0.01-0.38(0.16)$ & $3(43 \%)$ \\
\hline & & $(-) n=1$ & 0 & $1(100 \%)$ \\
\hline & & NT $n=1$ & & $1(100 \%)$ \\
\hline & $(-) n=15$ & $(+) n=5$ & $0.01-0.09(0.054)$ & $1(20 \%)$ \\
\hline & & $(-) n=7$ & 0 & $3(43 \%)$ \\
\hline & & (NT) $n=3$ & & $1(33 \%)$ \\
\hline \multirow[t]{5}{*}{$(\mathrm{NT}) n=77$} & $(+) n=5$ & $(+) n=3$ & $0.01-0.11(0.053)$ & $2(67 \%)$ \\
\hline & & $(-) n=2$ & 0 & $1(50 \%)$ \\
\hline & $(-) n=72$ & $(+) n=3$ & $0.01-0.09(0.054)$ & $1(33 \%)$ \\
\hline & & $(-) n=15$ & 0 & $4(27 \%)$ \\
\hline & & $(\mathrm{NT}) n=54$ & & 7 (13\%) \\
\hline
\end{tabular}

SPT - skin prick test, f340 - specific lgE for cochineal extract (carmine red), Phadia (+) - positive test, (-) - negative test, NT - not tested. 
noted in 4 patients only. In the $\mathbf{3} 40$ carmine (+) group, carmine SPT was positive in $60 \%$ of the patients, while in the patients with negative $\mathrm{f3} 40$ results the positive SPT was found only in $11 \%$. The patients in the $\mathbf{f 3 4 0}$ carmine (+) group reported systemic symptoms more often than in the $\mathrm{f340}$ carmine (-) group (84 vs. 52\%, $p<0.02$ ).

In the $\mathrm{f3} 40$ carmine (+) group, carmine hypersensitivity was diagnosed in $37 \%$ of the patients. Within the ranges of $0.01-0.09,0.1-0.35$, and above $0.35 \mathrm{kU} / \mathrm{l}$, the percentage of positive challeges was $22 \%, 43 \%$, and $67 \%$, respectively.

\section{Placebo-controlled oral challenge - OC}

In the selected group for challenge, 33 patients agreed to undergo carmine OC, while 8 patients with SPT carmine (+) or f340 carmine (+) results were not challenged due to the lack of their consent, noncompli-

Table 2. Characteristics of patients with carmine allergy

\begin{tabular}{|c|c|c|c|c|c|c|c|c|c|c|c|c|c|c|c|}
\hline$\dot{2}$ & $\stackrel{8}{\stackrel{8}{\alpha}}$ & 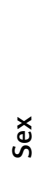 & $\stackrel{\mathrm{\Sigma}}{\mathrm{J}}$ & 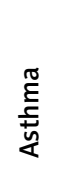 & 흘 & 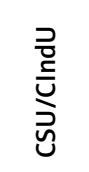 & 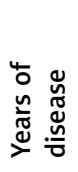 & 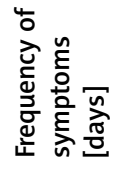 & 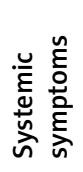 & 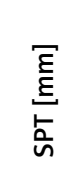 & 5 & 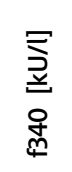 & 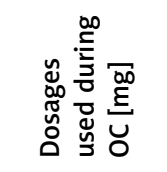 & 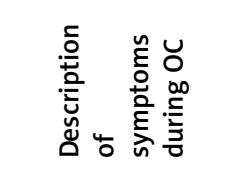 & 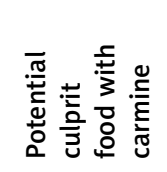 \\
\hline 1 & 31 & $\mathrm{~F}$ & $U+A E$ & No & Yes & $\begin{array}{l}\text { CSU/ } \\
\text { CIndU }\end{array}$ & 4.0 & $<7$ & Yes & (3) $5^{*}$ & Neg & 0.02 & $1-2-2-5-10$ & $\begin{array}{c}20 \text { min after } 2 \mathrm{mg} \\
\text { - itchiness, } 4 \mathrm{~h} \\
\text { after } 10 \mathrm{mg}- \\
\text { massive U/AE, } \\
\text { after } 24 \mathrm{~h}-\mathrm{U} / \mathrm{AE}\end{array}$ & Sweets \\
\hline 2 & 56 & $\mathrm{~F}$ & U & No & Yes & $\begin{array}{l}\text { CSU/ } \\
\text { ClndU }\end{array}$ & 7.0 & $<7$ & Yes & 0 & Neg & 3.05 & $\begin{array}{c}0.1-0.2-0.5- \\
1-2\end{array}$ & $\begin{array}{c}10 \text { min after } 2 \mathrm{mg} \\
\text { - urticaria } \\
\text { and stomach } \\
\text { disturbance }\end{array}$ & 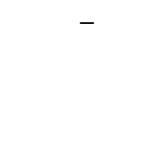 \\
\hline 3 & 39 & $\mathrm{~F}$ & U & No & Yes & $\begin{array}{l}\text { CSU/ } \\
\text { ClndU }\end{array}$ & 1.3 & $<7$ & Yes & 0 & Neg & 0 & $\begin{array}{l}1-2-5-10- \\
25-50\end{array}$ & $\begin{array}{l}20 \text { min after } 50 \\
\text { mg } \\
\text { - massive } \\
\text { urticaria, tingling } \\
\text { of the tongue }\end{array}$ & Kebab, pizza \\
\hline 4 & 75 & $M$ & $\mathrm{AE}$ & No & Yes & CIndU & 11.0 & $7-30$ & Yes & 6 & NT & 0.99 & SPT & $\begin{array}{l}40 \text { min after SPT } \\
\text { - oedema of the } \\
\text { tongue }\end{array}$ & $\begin{array}{l}\text { Fruit drop } \\
\text { Mentos, fruity } \\
\text { yoghurt, cold } \\
\text { meats }\end{array}$ \\
\hline 5 & 34 & $\mathrm{~F}$ & $U+A E$ & No & Yes & CIndU & 9.0 & $>30$ & Yes & 4 & Neg & 0.11 & $\begin{array}{c}1-2-5-10- \\
25-50-100- \\
150\end{array}$ & $\begin{array}{l}2 \mathrm{~h} \text { after } 150 \mathrm{mg} \\
\text { - massive urticaria }\end{array}$ & $\begin{array}{l}\text { Fruit jelly, } \\
\text { a some cakes }\end{array}$ \\
\hline 6 & 32 & $M$ & $U+A E$ & No & No & CIndU & 2.4 & $>30$ & No & 0 & Neg & 0 & $\begin{array}{c}1-2-5-10- \\
25-50-100- \\
150\end{array}$ & $\begin{array}{l}3 \mathrm{~h} \text { after } 150 \mathrm{mg} \\
\text { - oedema of the } \\
\text { mouth }\end{array}$ & Cold meats \\
\hline 7 & 44 & $\mathrm{~F}$ & U & Yes & Yes & CIndU & 9.5 & $>30$ & Yes & (4) $8^{+}$ & Neg & 0.16 & $\begin{array}{c}1-2-5-10- \\
25-100\end{array}$ & $\begin{array}{c}10 \text { min after } 5 \mathrm{mg} \\
\text { - erythema of the } \\
\text { neck and face, } \\
10 \mathrm{~min} \text { after } \\
100 \mathrm{mg} \text { - eyelid } \\
\text { oedema }\end{array}$ & $\begin{array}{l}\text { Raisins, } \\
\text { cranberry }\end{array}$ \\
\hline 8 & 28 & $\mathrm{~F}$ & U & Yes & Yes & CIndU & 10.0 & $>30$ & Yes & 5 & Neg & 0.11 & $\begin{array}{c}0.1-0.2-0.5- \\
1-2-5\end{array}$ & $\begin{array}{l}10 \text { min after } 5 \text { mg } \\
\text { - erythema of } \\
\text { neckline and } \\
\text { itchiness of throat } \\
\text { and skin }\end{array}$ & 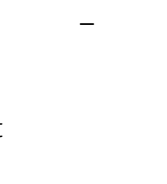 \\
\hline 9 & 26 & $\mathrm{~F}$ & $U+A E$ & No & No & CIndU & 4.5 & $>30$ & Yes & 0 & Neg & 0.02 & $\begin{array}{l}1-2-5-10- \\
25-50-100\end{array}$ & $\begin{array}{l}20 \text { min after } \\
100 \mathrm{mg} \\
\text { - massive } \\
\text { urticaria and } \\
\text { dyspnoea }\end{array}$ & $\begin{array}{l}\text { Ready salad, } \\
\text { Thai food }\end{array}$ \\
\hline
\end{tabular}

${ }^{*}$ SPT result after $30 \mathrm{~min}$ and $4.5 \mathrm{~h}$, ${ }^{\mathrm{t} S P T}$ result after $30 \mathrm{~min}$ and $2 \mathrm{~h}$. No. - number of the patient, $\mathrm{F}$ - female, $M-$ male, $U-$ urticaria, AE - angioedema, CSU chronic spontaneous urticaria, CIndU - chronic inducible urticaria, Neg-negative result, NT - not tested, SPT - skin prick test, PT - patch test, f340 - specific IgE for cochineal extract (carmine red) - Phadia, OC - oral challenge test, $h$ - hours. 

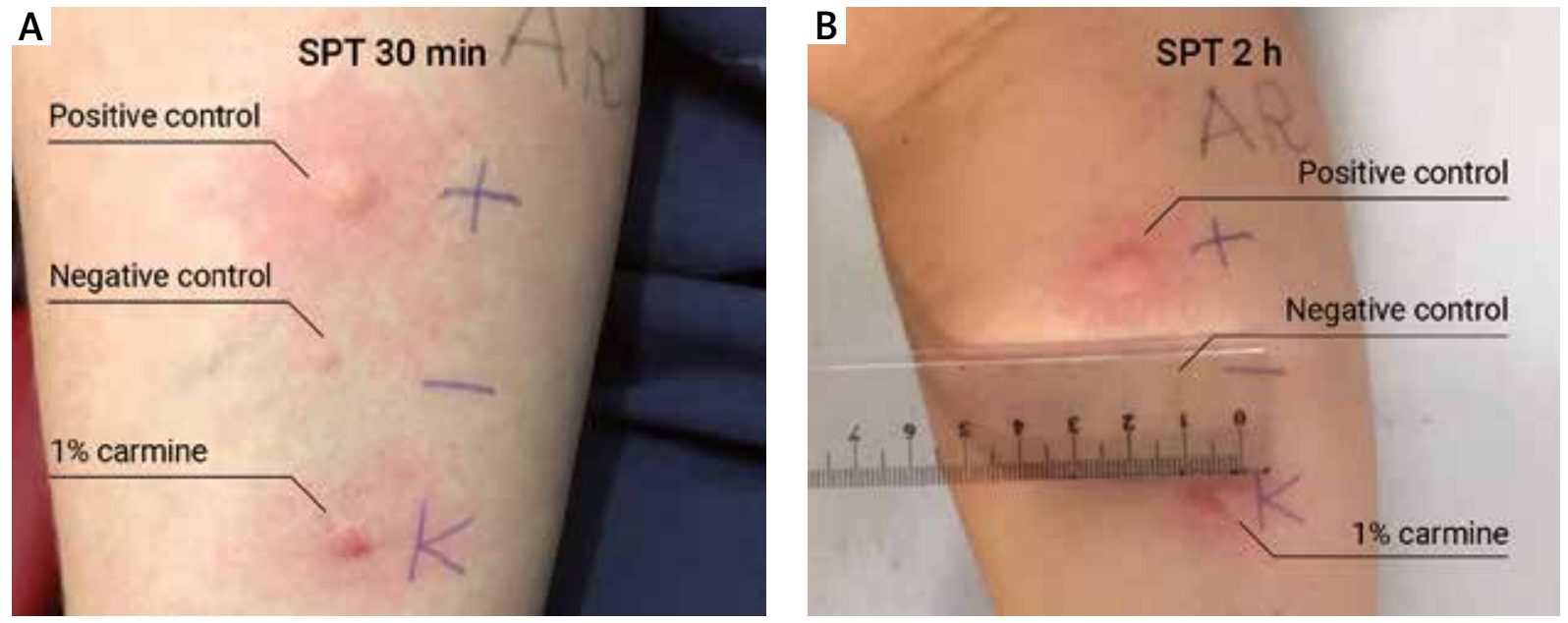

Figure 2. Carmine skin prick tests results after $30 \mathrm{~min}(\mathbf{A})$ and $2 \mathrm{~h}$ (B); patient no. 7; histamine intolerance as a concomitant disease

ance or contraindications. The OC was positive in eight out of 33 subjects, whose results are described (Table 2). The extended protocol with an initial dose of $0.1 \mathrm{mg}$ was performed in 2 patients, while the rest were initially challenged with a $1 \mathrm{mg}$ dose. Allergic symptoms during the OC were observed after $2 \mathrm{mg}$ in 2; $5 \mathrm{mg}$ in 2; $50 \mathrm{mg}$ in 1; $100 \mathrm{mg}$ in 1 and after $150 \mathrm{mg}$ in 2 patients. The most common skin reaction during the challenge was generalized urticaria, facial or neck erythema, angioedema and generalized pruritus. All the symptoms resolved after 1 or $2 \mathrm{~h}$ of treatment with 2 tablets of antihistamines and glucocorticoids if needed. Any adrenaline administration during the OC was not used. In the group diagnosed with allergy to carmine, in 5 out of 9 patients (56\%) the SPT result was positive, always with the wheal size of min. $4 \mathrm{~mm}$, and in 7 out of 9 patients (78\%) the 3340 result was min. $0.02 \mathrm{kU} / \mathrm{l}$. In 2 patients indicating kebab and sausages as a possible culprit food, with both SPT and $\mathrm{f340}$ being negative, a positive challenge was obtained. Compared to the rest of the study cohort, all the patients in the carmine hypersensitivity $(+)$ group had a history of more common facial symptoms (100 vs. $82 \%, p<0.02$ ) and systemic symptoms (89 vs. 53\%, $p<0.02)$

\section{Discussion}

This is the first study on carmine hypersensitivity in Poland using skin prick tests and slgE level measure- ment. Our study shows a significant number of patients with carmine allergy (8\%) in urticaria cohort, all of them with CIndU, while one-third of them had coexisting CSU. This shows the complexity of urticaria and its exacerbations.

Liippo et al. studied a group of 3164 patients with suspected food hypersensitivity and obtained positive carmine SPT results in 3\% of them [19]. In our patients, carmine SPT was positive in up to $17 \%$ of the subjects, what may result from the selection for the study made on the basis of the questionnaire. As confirmed by Greenhawt et al. [3, 20], the wheal size was larger after 30 min than after 20 min evaluation in all our patients, which shows that the skin reaction during carmine SPT should not be read until 30 min have passed. In patients 1 and 7 the skin reaction increased to the maximum size after 4 and $2 \mathrm{~h}$, which indicates the need to observe the skin for the next few hours after the prick.

The previous studies used different carmine concentrations for skin prick tests: $0.5 \%$ [7, 14-16], 1\% [21, 22] or even higher $[9,20]$. By testing with different SPT concentrations, we have shown that positive results were sometimes obtained with lower carmine concentrations. However in present urticaria patients, $1 \%$ carmine gave clearly positive results, especially in the subjects with dermographism, where negative control usually caused a wheal. Kägi et al. reported patients with anaphylaxis and acute angioedema after a Campari drink, whose 0.5\% carmine SPT was negative, while they were positive

Table 3. Skin prick test (SPT) and f340 sensitivity and specificity in patients with carmine allergy

\begin{tabular}{lcccc}
\hline Variable & Sensitivity (\%) & Specificity (\%) & PPV (\%) & NPV (\%) \\
\hline SPT & 56 & 63 & 36 & 79 \\
\hline f340 & 78 & 40 & 37 & 80 \\
\hline
\end{tabular}

SPT - skin prick test, f340 - specific IgE for cochineal extract (carmine red), Phadia; PPV-positive predictive value, NPV - negative predictive value. 
with carmine provided by drink manufacturers. It may only suggest that the $0.5 \%$ SPT concentration may not be sufficient in some patients [15].

In the SPT carmine (+) group, $83 \%$ of the patients had a positive $\mathrm{f340}$ result, while in the $\mathrm{f340}$ carmine (+) group, $60 \%$ of positive skin carmine tests were observed. Positive results for both SPT and $\mathrm{f340}$ were noticed in 15 (14\%) patients. In our cohort, the skin prick test was a more specific marker (63\%), while the 3440 was a more sensitive (78\%) one, which is presented in Table 3; however the cut-off point has been set at the minimum level of $0.01 \mathrm{kU} /$ l. Low carmine slgE levels in patients with E120 allergy were reported in previous studies. Voltolini et al. determined angioedema reactions in a female patient after ingestion of meat with carmine with slgE of $0.19 \mathrm{kU} / \mathrm{l}[1]$.

Takeo et al. have proposed an interesting diagnostic chart for patients with suspected carmine allergy [18]. In Japan, the addition of carmine to food is not allowed there albeit cochineal is permitted, while there are no restrictions on the practice of adding carmine to cosmetics. This may be the reason behind anaphylaxis being observed in patients, who have eaten food imported from Europe, what may suggest that Japanese people are 'more sensitive' to carmine ingestion.

These Japanese authors recommend that the positive SPT result and the medical history suggesting carmine hypersensitivity should confirm the diagnosis of carmine allergy. They further recommend that only the level of slgE should be checked when - despite negative skin tests - a history of allergy is suspected (the condition observed in $20 \%$ of their patients) [18]. In our subject group we performed nine carmine $O C$ in patients with negative SPT and $\mathrm{f3} 40$ value of 0-0.09 kU/l and obtained three positive results. Patient 9 , a non-atopic individual with $\mathrm{f} 340$ at a level of $0.02 \mathrm{kU} / \mathrm{l}$, developed massive urticaria with dyspnoea 20 min after a 100 mg dose administration. Additionally, patients 3 and 6 with reported reactions after eating food with carmine, namely they experienced urticaria and angioedema during the challenge despite their negative SPT and f340 tests. Still, in two men whose SPT and 340 figures were 5 and $3 \mathrm{~mm}$ and 0.31 and $0.38 \mathrm{kU} / \mathrm{l}$, respectively, the result of the challenge was unexpectedly negative. Accordingly, every patient with positive SPT or $\$ 340$ above $0.01 \mathrm{kU} / \mathrm{l}$ may be clinically relevant and requires an oral challenge.

The wheal size of $\min .4 \mathrm{~mm}(n=10)$ always coexisted with a positive result of $\mathrm{f340}$, yet a negative OC was obtained in this group in three subjects. It is therefore an open question whether in the case of sensitization and negative oral challenge patients should avoid carmine consumption. We would be careful to allow carmine to be consumed in this patient group. Nearly $44 \%$ of the patients with positive SPT and negative OC clearly indicated that their symptoms manifested after eating foods such as salami, other meat products, kebabs, sweets and fruit yoghurts. Although the carmine content in foods is strictly defined, in practice the recommended dose limits may be exceeded [23]. We cannot exclude that some reactions are dose-dependent or associated with other co-factors.

Liippo et al. showed that $41 \%$ of the patients with a positive carmine SPT reported symptoms after exposure to the dye [19]. In our study, as much as 58\% of the patients indicated carmine food as a potential cause of symptoms, this percentage being higher than that in the carmine SPT negative group $(23 \%, p<0.003)$.

Some researchers believe that epidermal damage, e.g. to the eyelids in atopic patients does promote sensitization [4]. Our study seems to confirm this because we have found a statistical predominance of atopy in each group with positive carmine tests.

Carmine allergy is believed to be a consequence of skin exposure to carmine cosmetics [24-27]. The level of carmine concentrations has been revealed by one of the cosmetics company: $0.01-4 \%$ in lipsticks, $0.05-10 \%$ in blushes, and $0.02-20 \%$ in eye shadows [24]. Patients 2, 3, 7 and 9 were still using cosmetics with E120 (eye shadows, blushes or lipsticks). Having stopped using her eye shadow, patient 7 was free of chronic eyelid oedema she had complained about for 2 years, the condition that worsened during the OC. Still, patients 1, 4 and 8 had used cosmetics with carmine in the past. In our patient group, as many as seven men were positive with a minimum of one carmine test (4 SPT, 7 f340, 2 OC), but the source of E120 sensitization was not established. In all the patients with positive OC, carmine patch tests were definitely negative, so we did not find any contact allergy coexistence. Other authors showed positive carmine patch tests in children, however no oral challenge was performed [28, 29].

\section{Conclusions}

Carmine allergy in urticaria is more common than it was previously suspected, especially in patients with atopy and systemic symptoms in the course of chronic inducible urticaria. In diagnosing hypersensitivity to carmine, particular attention should be paid to reactions occurring after indigestion of fruit yoghurts, coloured sweets, kebabs and other meats. As the first allergic symptom can be anaphylaxis, it is worth considering whether avoiding carmine both in the diet and in cosmetics in E120 sensitive patients is optimal. A skin prick test and the slgE evaluation combined with a detailed medical history focused on the culprit foods seem to be helpful diagnostic tools in determining hypersensitivity to carmine in urticaria patients.

\section{Acknowledgments}

The authors want to acknowledge Mikołaj Rybaczuk, MA for statistical analysis. 


\section{Conflict of interest}

The authors declare no conflict of interest.

\section{References}

1. Voltolini S, Pellegrini S, Contatore M, et al. New risks from ancient food dyes: cochineal red allergy. Eur Ann Allergy Clin Immunol 2014; 46: 232-3.

2. Müller-Maatsch J, Gras C. The 'carmine problem' and potential alternatives. In: Handbook on Natural Pigments in Food and Beverages. Industrial Applications for Improving Food Color. Carle R, Schweiggert R (eds). Elsevier 2016; 385-428.

3. Greenhawt MJ, Baldwin JL. Carmine dye and cochineal extract: hidden allergens no more. Ann Allergy Asthma Immunol 2009; 103: 73-5.

4. Miyakawa M, Inomata N, Sagawa N, et al. Anaphylaxis due to carmine-containing foods induced by epicutaneous sensitization to red eye-liner. J Dermatol 2017; 44: 96-7.

5. Sadowska B, Chełmińska M. Carmine - overlooked allergen in diagnostic of immediate and delayed idiopathic hypersensitivity. Alergol Pol 2019; 6: 30-8.

6. EFSA ANS Panel (EFSA Panel on Food Additives and Nutrient Sources added to Food), 2015. Scientific Opinion on the reevaluation of cochineal, carminic acid, carmines (E120) as a food additive. EFSA J 2015; 13: 4288.

7. Ferrer A, Marco FM, Andreu C, et al. Occupational asthma to carmine in a butcher. Int Arch Allergy Immunol 2005; 138: 243-50.

8. Taylor SL, Hefle SL. Ingredient and labeling issues associated with allergenic foods. Allergy 2001; 56 Suppl 67: 64-9.

9. Chung K, Baker Jr JR, Baldwin JL, et al. Identification of carmine allergens among three carmine allergy patients. Allergy 2001; 56: 73-7.

10. Pecquet C. Allergic reactions to insect secretions. Eur J Dermatol 2013; 23: 767-73.

11. Dapson RW. The history, chemistry and modes of action of carmine and related dyes. Biotech Histochem 2007; 82: 173-87.

12. Nordic Council of Ministers. Food additives in Europe 2000 - Status of safety assessments of food additives presently permitted in the EU. TemaNord 2002; 560: 87-91.

13. Ohgiya Y, Arakawa F, Akiyama H, et al. Molecular cloning, expression, and characterization of a major 38-kD cochineal allergen. J Allergy Clin Immunol 2009; 123: 1157-62.

14. Liippo J, Lammintausta K. Allergy to carmine red (E120) is not dependent on concurrent mite allergy. Int Arch Allergy Immunol 2009; 150: 179-83.

15. Kägi MK, Wüthrich B, Johansson SG. Campari-orange anaphylaxis due to carmine allergy. Lancet 1994; 344: 60-1.

16. Wüthrich B, Kägi MK, Stücker W. Anaphylactic reactions to ingested carmine (E120). Allergy 1997; 52: 1133-7.

17. Dietemann-Molard A, Braun JJ, Sohier B, et al. Extrinsic allergic alveolitis se-condary to carmine. Lancet 1991; 338: 460.

18. Takeo N, Nakamura M, Nakayama S, et al. Cochineal dye-induced immediate allergy: review of Japanese cases and proposed new diagnostic chart. Allergol Int 2018; 67: 496-505.

19. Liippo J, Lammintausta K. An oral challenge test with carmine red (E120) in skin prick test positive patients. Eur Ann Allergy Clin Immunol 2015; 47: 206-10.

20. Greenhawt M, McMorris M, Baldwin J. Carmine hypersensitivity masquerading as azithromycin hypersensitivity. Allergy Asthma Proc 2009; 30: 95-101.

21. Burge PS, O'Brien IM, Harries MG, et al. Occupational asthma due to inhaled carmine. Clin Allergy 1979; 9: 185-9.
22. Tabar Al, Acero S, Arregui C, et al. Asthma and allergy due to carmine dye. Ann Sist Sanit Navar 2003; 26 (Suppl 2): 65-73.

23. Heydari R, Hosseini M, Zarabi S. A simple method for determination of carmine in food samples based on cloud point extraction and spectrophotometric detection. Spectrochim Acta A Mol Biomol Spectrosc 2015; 150: 786-91.

24. Shaw DW. Allergic contact dermatitis from carmine. Dermatitis 2009; 20: 292-5.

25. Suzuki K, Hirokawa K, Yagami A, et al. Allergic contact dermatitis from carmine in cosmetic blush. Dermat Contact Atopic Occup Drug 2011; 22: 348-9.

26. Beaudouin E, Kanny G, Lambert $\mathrm{H}$, et al. Food anaphylaxis following ingestion of carmine. Ann Allergy Asthma Immunol 1995; 74: 427-30.

27. Katada Y, Harada Y, Azuma N, et al. 494 Skin sensitization to carmine before onset of systemic allergy to ingested carmine. World Allergy Organ J 2012; 5 (Suppl 2): S174.

28. Catli G, Bostanci I, Ozmen S, et al. Is patch testing with food additives useful in children with atopic eczema? Pediatr Dermatol 2015; 32: 684-9.

29. Ozceker D, Dilek F, Yucel E, et al. Can allergy patch tests with food additives help to diagnose the cause in childhood chronic spontaneous urticaria? Adv Dermatol Alergol 2020; 37: 384-9. 